\title{
The Role of Observation and Control in Laboratory and Field Research Settings
}

Amedeo Giorgi

Saybrook Institute

\section{Introduction}

Most of mainstream psychology today still entertains as an ideal the desirability of doing laboratory research. To be sure, much research is done outside the laboratory, but it is usually prefaced with special justifications or rationalizations because field work is seen as a compromise to be accepted rather than a desideratum. The primary reason for this seems to be the fact that the myth of the "laboratory as science par excellence" has been accepted by psychology. Even in those cases where necessity has forced psychologists to use other methods, the criteria of the "idealized lab" haunt them. For example, Ickes (1983, p. 19), after describing how the constraints of traditional methods forced him to take a naturalistic turn, concludes "it is possible to combine many of the best features of laboratory and field-observational research within a single basic paradigm for the study of unstructured dyadic interaction." My question is: Why is it even desirable to try to introduce some of the criteria of laboratory methods into field research? Are not the situations so different that a different set of criteria should apply? Is not the emergence of field research or "naturalistic observation" precisely due to the fact that the procedures of the laboratory were too restricted, because they were geared for a very specific type of situation and other procedures were demanded? The purpose of this paper is to show that naturalistic research is a special type of research situation that requires its own procedures, and that one does not have to use the criteria of the laboratory to evaluate it or confound it. Or better, this essay will try to show that laboratory and field research are variations of a deeper sense of research rigor and that a phenomenological approach is crucial in helping us understand this deepened sense of rigor.

\section{Mode of Presence and Laboratory and Field Research}

That the two research situations are concretely different is not hard to demonstrate. One of the very first scientists to use naturalistic observation, J.H. Fabre, described the difference between the two situations as follows:

Once the chemist has worked out his plan of research after mature deliberation, he mixes his reagents and lights his Bunsen burner whenever convenient. $\mathrm{He}$ is master of time, place, and circumstance. He chooses his own time; he isolates himself in his laboratory retreat where nothing will distract him from his labors; he creates at will this or that condition 
as reflection may suggest. ... The secrets of living nature, however, create much more difficult and precarious working conditions for the observer of life in action. Far from being able to arrange his own time, he is the slave of the season, of the day, of the hour, of the very moment. If an opportunity arises, it must be seized on the fly without hesitation, for a long time may pass before it comes again. And since opportunity usually knocks when least expected, nothing is ready to make the most of the occasion. On the spot, experimental materials must be improvised, tactics adjusted, rules devised. ... Furthermore, this chance comes only to the observer who seeks it. He must stalk it patiently for days and days. [omissions in original] (Ruwet, 1972, pp. 14-15)

Thus, right at the very beginning of the turn to naturalistic observation as a mode of doing science, sharp differences between the laboratory approach and the field approach are observed. The key differences are that in the laboratory, the researcher is "master of time, place, and circumstance ... [and] he creates at will this or that condition..." whereas the "observer of life in action ... is the slave of the season, of the day, of the hour, of the very moment," and if an opportunity does arise, "it must be seized on the fly without hesitation."

This difference, which still exists, raises questions about observation and control, their relationship, and how to interpret and implement them in psychological research. Only by clarifying these intricate issues can we come to the realization that research in naturalistic settings is not "second rate" and can we show that the same sense of rigor is being fulfilled in each situation, but in a different way, precisely because the two situations are so different. In other words, the differences between the two types of research are related precisely to the conditions and not to the goal, which remains constant, and which, given the differences in the conditions, is met equally well in a theoretical sense. In order to demonstrate this point, it is necessary to make reference to the presence of the researcher, because only in terms of such a reference can the very idea of a goal of research make sense.

The above statement by Fabre already shows how the presence of the researcher must vary according to the two settings. Let us demonstrate this a little more with another description, but this time by Duhem, where the point being established is the complexity of the term "observation."

Enter a laboratory; approach the table crowded with an assortment of apparatus, an electric cell, silk-covered copper wire, small cups of mercury, spools, a mirror mounted on an iron bar; the experimenter is inserting into small openings the metal ends of ebony-headed pins; the iron bar oscillates, and the mirror attached to it throws a luminous band upon a celluloid scale; the forward-backward motion of this spot enables 
the physicist to observe the minute oscillations of the iron bar. But ask him what he is doing. Will he answer "I am studying the oscillations of an iron bar which carries a mirror?" No, he will say that he is measuring the electrical resistance of the spools. If you are astonished, if you ask him what his words mean, what relation they have with the phenomenon he has been observing and which you have noted at the same time as he, he will answer that your questions require a long explanation and that you should take a course in electricity. (Hanson, 1971, p. 4)

What this description irrefutably brings out is the role of "knowledge" in laboratory observation. Without the proper background, one could not even "see" the meanings that the physicist sees in the laboratory. Moreover, the Fabre quote shows how such knowledge even influences expectations because "On the spot, experimental materials must be improvised, tactics adjusted, rules devised."

What we are trying to establish with these descriptions is that the presence of the researcher brings a very complicated presence to the research situation, and the relative validity of both laboratory and field research is related to this complicated structure. We can describe it as an intentional relation to the research situation that minimally includes the following structure: background knowledge-ongoing preceptions - expectational set. Let us now try to understand observation and control in terms of this conscious structure of the researcher.

\section{The Meanings of Observation and Control}

What the two research situations really seem to trade are observation and control. It seems as if the laboratory is a place where the concern is first for controls and then observation and the field situation is one where observation dominates and controls are haphazard. But such a description is simplistic because the actual situation is far more complicated. Let us look more closely.

The trouble begins with the meaning of the key terms: observation and control. If we allow that in everyday life we normally perceive or look at events, then one could say that observation means regarding things more closely, with more interest, or indeed one could call it seeing systematically or with a sense of expectation. Indeed, the dictionary gives as one of the meanings of observe "to watch attentively." It also states that implied in the meaning of observe is the sense of abiding or adhering to a "law, duty, custom, decision," and so forth. Thus a sense of knowledge and guidance with respect to a situation or event is implied in the very meaning of observation. In other words, observation already incorporates a sense of control within it. Therefore, in clarifying the first term, the difference between perceiving or looking in the ordinary sense and observing, has to be noted, which implies in part that observing is attending or perceiving with control. 
Now let us turn to the meaning of control. Here, too, some distinctions have to be made. In the laboratory setting, control practically comes to mean manipulate. That is because the laboratory setting is itself the creation of the scientist, and it is deliberately created in order for the researcher to be able to dictate to the situation. Anything that is left to chance is seen as a demerit. The dictionary confirms these ideas by defining control as exercising "authority or dominating influence over; to hold in restraint or check; to direct or regulate." Thus a strong sense of control means being able to do things at will, to be able to have desires transformed into realities in as brief a time as it takes to accomplish the task.

However, control does not have to be defined so narrowly. It could mean to be respectfully present in a situation so that one could respond knowledgeably and appropriately with readiness to the perceived spontaneous happenings of a situation. In this sense, control refers to a certain kind of "intentional presence," a certain way of looking, an informed being present that at the same time does not actively intervene in the unfolding of the event to be observed. In terms of the structure of consciousness of the previous section, the knowledge that the researcher has guides his expectations so that he knows how to interpret or evaluate his ongoing perceptions. The researcher can do this without active intervention, but it is still a form of control because directedness and restraint are used by the researcher in perceiving the situation. Thus control implies observation, that is, it is an educated looking.

Thus there is a certain redundancy when one uses both observation and control, and that is because they belong to the same situation. Observation generally refers to the sensory or cognitive aspect of the researcher's participation, and control to his or her behavioral or action aspect, with controls sometimes referring to the environmental characteristics of the research situation. The redundancy is due to the fact that both words refer to a situation that is meant to be carefully examined and approached as knowledgeably as possible and with circumscribed expectations. How these factors are implemented depends upon the attitude adopted by the researcher and the extent to which the research situation is understood integratively.

\section{Attitude and Observation and Control}

The above analyses suggest that there is a difference in how observation and control are implemented, depending on the attitude of the researcher. In a mastery attitude, domination is sought and manipulation of the situation is the means. Manipulation is control in the sense of mastery and the laboratory symbolizes total mastery of a situation. To manipulate means to be able to bring into being, at will, a specified set of circumstances and, therefore, to be able to vary circumstances in order to discover the effects of induced changes. In a dialogical attitude, precise understanding is sought 
and description of the situation's unfolding is the means. In a dialogical setting, control simply means being able to perceive or understand certain effects that are taking place relatively spontaneously. One wants knowledge of the event, but one wants to know about it as it would take place on its own and therefore one allows it to become what it will be by giving it the space to do so.

It is easy to see, therefore, that the laboratory is strong on intervention and manipulation of specifics, whereas field research is more passive and responsive, but both situations are what they are precisely in the name of rigor. But even this understanding can be deepened. What really differentiates the mastery sense of observation and control from the dialogical sense is the degree of the situation allowed to unfold spontaneously. Surprisingly, perhaps, such spontaneity is not altogether missing in the laboratory. Rather, it is merely narrowed to the greatest extent possible. For example, even in a laboratory setting one must allow the dependent variable to express itself insofar as it is the alleged effect of changes in the controlled circumstances. It is the one thing that is not controlled, because it is interpreted to be the outcome of all of the manipulated changes that the researcher introduced (allowing for error). Theoretically, what is significant here is that even controlled situations have to allow for some spontaneity; otherwise nothing new is ever learned.

In field research, at least in the human sciences, the zone of spontaneity is extended to the situation as it is for the subject undergoing the experience. This is really the critical difference, for where human subjects are concerned, one cannot merely assume that their experience or behaviors are causally dependent on the manipulations of the researcher, but only that the manipulations will have some type of influence on the subjects. The full meaning of the responses really depends on how the manipulations are taken up by the subjects. Thus one must stand back and observe how subjects relate to their situations. In other words, with humans it is recognized that the "zone of spontaneity" is much larger and not in the hands of the researcher. The researcher can only create a space within which an "in principle" nonmanipulable activity can take place. Thus control in the sense of manipulation seems not to be the desirable mode of presence for research with human subjects.

\section{Empirical versus Phenomenological Interpretation of Research Settings}

The laboratory, of course, developed primarily within the context of empirical philosophy which gave a high priority to sensory-perceptual givens that were publicly verifiable, and it tended to downplay the conscious processes of the researcher. Consequently, in such a 
perspective the criteria used for "observing and controlling" were always couched in terms of sensory and public manifestations. The conscious processes of the researcher were not thematically considered.

This understanding of the research situation is too limiting, especially for a phenomenological perspective. The difference comes down to whether the criterion for observation and control is a physical object or situation as simply perceived, or the meaning of such an object or situation. Traditional laboratory researchers make the first the criterion, because of the philosophy of science that they adopt which demands that the perceived object be given in a sensory-perceptual manner and in a public way. A phenomenological theory of science dictates that the criterion be in terms of the relationship between the object and the act of consciousness in which the object appears (including its modality), because there is no way to avoid the act. Either it is taken into account, or else it is silently taken for granted. But if it remains merely taken for granted, then one is being less rigorous than one can be and that would dictate against one of the key criteria of experimental science. Following this reasoning, then, both the object perceived (or aspect of the event perceived) and the acts through which it is presented would have to be analyzed in order to have a clear understanding of control and observation in both laboratory and naturalistic settings.

But the case for including the structures of consciousness of the researcher are even stronger because laboratory settings are not haphazardly discovered but planned. Insofar as the manipulations are planned, they are the implementations of ideas that precede them. To have certain ideas about a situation means to be present to the situation in a rationally anticipatory way. The point here, then, is that even laboratory situations are preceded by an anticipatory presence of the same situation for the consciousness of the researcher. Moreover, this anticipatory presence to the laboratory is not much different from the expectatory set of the field researcher. Both have moments when they have to be aware of "merely" intentional presences, and then at some point in time actual perceptual givens replace the intentional presences. The difference is that the laboratory researcher can control the timing and degree of presence of the actual perceptions, whereas the field researcher must wait for them to happen. It is obvious that background knowledge is important for what is to be expected, and expectations help to interpret what is perceived. The dynamic relationships among background, expectations, and perceptions are active for both situations, and that is why it was stated above that the true difference between laboratory and field is the attitude: the former mastery, the latter dialogical. 
Background knowledge and research interest help the laboratory researcher to structure a situation, but they also help the field researcher to observe. Indeed, in naturalistic research, to observe systematically and to allow for proper control coalesce into the same thing, which is to perceive the unfolding of the event in a careful but intelligible way. To seriously object to this strategy would mean that one would also have to object to the planning procedures of laboratory research. Thus both really desire rigor but because of different circumstances each has to go about it a different way. Only by appealing to the intentional presence of the researcher's consciousness can one show that a common aim is being met in both ways. Consequently, laboratory and field research are really equal with respect to rigor, and the latter should not be viewed as a lesser possibility, nor should their criteria be confounded.

\section{References}

Hanson, N.R. (1971). Observation and explanation. New York: Harper \& Row.

Ickes, W. (1983). A basic paradigm for the study of unstructured dyadic interaction. In H.T. Reis (Ed.), Naturalistic approaches to studying social interaction (pp. 5-21). San Francisco: Jossey-Bass.

Ruwet, J.C. (1972). Introduction to ethology (J. Diamanti, Trans.). New York: International Universities Press. 